\title{
Cuidado ecológico como um fenômeno amplo e complexo
}

\author{
Ecological care as a broad and complex phenomenon \\ Atención ecológica como un fenómeno amplio y complejo
}

\section{Marli Terezinha Stein Backes', Dirce Stein Backes", Lívia Crespo Drago"', Magda Santos Koerich"v, Alacoque Lorenzini Erdmann ${ }^{\mathrm{V}}$}

' Universidade Federal de Pelotas, Hospital Escola. Pelotas-RS, Brasil. Universidade Federal de Santa Catarina, Grupo de Estudos e Pesquisas em Administração e Gerência do Cuidado em Enfermagem e Saúde, Programa de Pós-Graduação em Enfermagem. (Doutoranda) Florianópolis-SC, Brasil.

"Centro Universitário Franciscano, Departamento de Enfermagem. Santa Maria-RS, Brasil.

Universidade Federal de Santa Catarina, Grupo de Estudos e Pesquisas em Administração e

Gerência do Cuidado em Enfermagem e Saúde. Florianópolis-SC, Brasil.

II' Universidade Federal de Santa Catarina, Curso de Graduação em Enfermagem, Grupo de Estudos e

Pesquisas em Administração e Gerência do Cuidado em Enfermagem e Saúde. Florianópolis-SC, Brasil.

IV Universidade Federal de Santa Catarina, Departamento de Patologia, Grupo de Estudos e

Pesquisas em Administração e Gerência do Cuidado em Enfermagem e Saúde. Florianópolis-SC, Brasil.

v Universidade Federal de Santa Catarina, Programa de Pós-Graduação em Enfermagem, Grupo de Estudos e Pesquisas em Administração e Gerência do Cuidado em Enfermagem e Saúde. Pesquisadora CNPq. Florianópolis-SC, Brasil.

Submissão: 11-03-2010 Aprovação: 21-02-2011

\section{RESUMO}

Este estudo objetivou compreender o significado do cuidado ecológico na visão de estudantes e docentes da área da saúde de uma Instituição Pública de Ensino Superior. Pesquisa qualitativa exploratória, conduzida pelo método da Teoria Fundamentada nos Dados, com dados oriundos de dez entrevistas semiestruturadas, realizadas entre setembro de 2008 e abril de 2009, constituindo dois grupos amostrais. O processo de coleta e análise dos dados culminou com a formulação da teoria "Vislumbrando o cuidado ecológico como um fenômeno amplo e complexo", discutida pelo olhar da complexidade. Concluise que o ambiente acadêmico constitui-se em espaço apropriado para o desenvolvimento de habilidades sistêmicas capazes de contemplar as relações, interações e associações necessárias para a compreensão e promoção da sustentabilidade ambiental. Descritores: Ecologia; Saúde; Enfermagem; Formação de recursos humanos; Desenvolvimento sustentável.

ABSTRACT
This study aimed to comprehending the meaning of ecological care from the point of view of students and teachers of the health area of a Public Institution of Higher Education. It was an exploratory qualitative research conducted by the method of the Theory Based on the Data, for which ten in depth interviews were carried out between September/2008 and April/2009, distributed in two sample groups. The process of data collection and analysis culminated with the formulation of the theory "Viewing ecological care as a broad and complex phenomenon", which was discussed through the view of complexity. One concluded that the academic environment is constituted by an appropriate space for the development of the systemic abilities, capable of contemplating the relations, interactions and necessary associations for the comprehension and promotion of the environmental sustainability.

Key words: Ecology; Health; Nursing; Human resources formation; Sustainable development.

\section{RESUMEN}

Este estudio tuvo como objetivo comprender el significado del cuidado ecológico en el punto de vista de estudiantes y profesores del área de la salud de una institución pública de educación superior. Se llevó a cabo un estudio cualitativo, por el método de la Teoría Fundamentada en los Datos, con datos de diez entrevistas, realizadas entre septiembre de 2008 y abril de 2009, formando dos grupos de la muestra. El proceso de recopilación y análisis de los datos llevaron a la formulación de la teoría de la "Promoción de la atención ecológica como un fenómeno amplio y complejo", discutida por el aspecto de la complejidad. Se concluye que el ambiente académico es el espacio apropiado para el desarrollo de habilidades sistémicas capaces de abordar las relaciones, interacciones y asociaciones necesarias para la comprensión y la promoción de la sostenibilidad del medio ambiente.

Palabras clave: Ecología; Salud; Enfermería; Formación de Recursos Humanos; Desarrollo Sostenible. 


\section{INTRODUÇÃO}

O cuidado abrange dimensões amplas e complexas que vão desde o cuidado de si, do outro, do meio ambiente, da natureza e do planeta como um todo. O cuidado, como um fenômeno complexo por excelência, necessita, cada vez mais, unir e integrar os diferentes aspectos vitais ameaçados pelo reducionismo mecanicista que desapropria a parte do todo e o todo da parte.

Pensar em cuidado é pensar no indivíduo, nas relações deste com os demais indivíduos e o meio em que vivem, ou seja, no ambiente ecológico, nas interações e associações que envolvem o sistema como um todo. A ecologia, entendida como sendo o estudo das relações entre os seres vivos e o meio ambiente, traz em si uma preocupação ética por parte de todos os atores sociais e se coloca como uma temática a ser abordada em todas as áreas.

O cuidado ecológico é uma atitude que impulsiona a atenção para a defesa do meio ambiente, tanto natural quanto relacional. Logo, esta atitude acontece em casa, nas escolas, nas universidades, no local de trabalho, ou seja, nos espaços públicos ou privados, por meio das relações e interações entre os seres humanos e demais seres presentes na natureza, num compromisso ético de cuidado consigo, com o outro e com o planeta, de forma integradora ${ }^{(1)}$.

O cuidado ecológico, neste sentido, abrange tanto o cuidado voltado para a ecologia humana como o cuidado voltado para a ecologia ambiental. Entretanto, a formação dos profissionais da área da saúde parece estar mais voltada para a ecologia humana, por ter como foco de atuação a saúde humana. Por outro lado, o modelo biomédico, cujo foco é a doença, ainda está fortemente presente na formação e atuação dos profissionais da saúde, acompanhada pelo conhecimento superespecializado, que ainda vê o indivíduo e o seu corpo de forma compartimentada, através dos órgãos e sistemas, ou seja, dividido em partes, para conhecê-lo e também para tratá-lo/cuidá-lo.

Por este motivo consideramos imprescindível que os profissionais da saúde tenham uma visão ampliada em saúde, que considere as diversas dimensões que integram a saúde humana, como já foi destacado pela Reforma Sanitária, na VIII Conferência Nacional da Saúde, bem como pelo Programa Nacional de Reorientação da Formação Profissional em Saúde (Pró-Saúde), os quais possibilitam e estimulam uma visão ampliada do conceito de saúde, pela apreensão e valorização das diferentes dimensões e associações, ou seja, como resultado das condições de alimentação, trabalho, habitação, educação, renda, meio ambiente, transporte, lazer, liberdade, acesso e posse da terra e acesso aos serviços de saúde ${ }^{(2-4)}$.

Por meio do conceito ampliado de saúde, sustentado pelo cuidado integral e integrador, os diferentes sistemas interagem e se autorreproduzem por meio do cuidado complexo. Desse modo, o conceito de saúde transcende a dimensão física e inclui a saúde mental, emocional, espiritual e também a saúde social e ambiental(5).

Esta nova apreensão do conceito de saúde, em sua dinamicidade e interatividade, pode ser considerada como sistêmica e é compreendida como o resultado das formas de organização social, que podem ocasionar grandes desigualdades sociais em função das influências favoráveis ou desfavoráveis e a multiplicidade de fatores físicos, psicológicos, sociais e ambientais, todos interdependentes e inter-relacionados numa cadeia sistêmica, aos quais é atribuída grande importância, principalmente no cenário econômico e político atual ${ }^{(6,7)}$.

A biosfera necessita da interação das consciências humanas e de forças organizativas profundas que ainda permanecem inconscientes, motivo pelo qual necessitamos de uma reforma do pensamento que, evidentemente, requer a reforma do processo ensino aprendizagem. Há uma dependência e interdependência nos fatos que fazem com que nós mesmos também possamos relacionar as partes ao todo, e ao mesmo tempo, nos incluindo neste todo ${ }^{(8)}$.

O ambiente acadêmico onde se dá a formação dos profissionais da saúde/enfermagem, é o espaço no qual os futuros profissionais devem ser sensibilizados e conscientizados para o aprendizado sistêmico que envolve os diversos aspectos da vida humana e a contextualização dos saberes, conhecimentos e práticas relacionados ao processo saúde-doença como um todo, de forma integrada.

Nesse sentido, a alfabetização ecológica, pela qual todos precisamos passar, tanto os estudantes quanto os docentes da área da saúde, além de pessoas leigas, governantes/políticos e a população em geral, e que deverá ser inspirada pela ética ambiental voltada para o cuidado com o planeta, através da mudança dos nossos hábitos de consumo ${ }^{(9,10)}$, vem ao encontro dos princípios da sustentabilidade ecológica/ambiental.

Nessa perspectiva, a educação em saúde precisa incorporar a complexidade das inter-relações sistêmicas da problemática ambiental, assim como a análise dos significados, valores e potencialidades sócio-culturais e ambientais, visando à construção de novas e mais complexas interações dos homens entre si e com a natureza, em suas diversas formas de expressão.

A partir do exposto e das crescentes indagações relacionadas à formação dos profissionais da saúde/enfermagem com base em uma visão sistêmica do conceito de saúde, a qual contempla o cuidado ecológico como possibilidade interativa e associativa para um viver melhor, o presente estudo está fundamentado na seguinte questão de pesquisa: Como os estudantes de graduação, futuros profissionais da saúde, significam o cuidado ecológico, levando em conta a sua inserção na academia, as suas interações, conexões e inter-relações. E tem como objetivo a compreensão do significado do cuidado ecológico na visão de estudantes de graduação e docentes da área da saúde de uma Instituição Pública de Ensino Superior.

O projeto inicial intitulado: "Significando o cuidado ecológico na visão dos estudantes da área da saúde de uma instituição pública", vincula-se à linha de pesquisa Administração em Enfermagem e Saúde, do Grupo de Estudos e Pesquisas em Administração e Gerência do Cuidado em Enfermagem e Saúde (GEPADES) do Programa de Pós Graduação em Enfermagem da Universidade Federal de Santa Catarina (UFSC) e integrou o Programa Interinstitucional de Bolsas de Iniciação Científica (PIBIC) 2008/2009. 


\section{MÉTODO}

Estudo qualitativo exploratório realizado pelo método da Teoria Fundamentada nos Dados (TFD) ou Grounded Theory ${ }^{(11,12)}$.

Para compor a amostragem teórica preconizada pela TFD, os dados foram coletados por meio da técnica de entrevista semiestruturada, em dois grupos amostrais. Para formar o primeiro grupo amostral foram convidados, aleatoriamente, um estudante do último ano de cada um dos cursos de graduação da área da saúde do Centro de Ciências da Saúde (CCS) de uma universidade pública, ou seja, da Enfermagem, Farmácia, Medicina, Nutrição e Odontologia, totalizando cinco participantes.

O questionamento que norteou as entrevistas do primeiro grupo, dentre outros que emergiram no decorrer do processo, foi: O que significa para você o cuidado ecológico e quais as suas implicações na saúde?

Um segundo grupo amostral foi formado com a participação de docentes, também escolhidos aleatoriamente e/ou por indicação de outros docentes, de cada um dos cinco cursos citados acima, com a finalidade de preservar e ampliar as hipóteses que emergiram da coleta e análise dos dados do primeiro grupo amostral. Dentre outros aspectos, as hipóteses acenaram para possíveis controvérsias relacionadas às metodologias de ensino aprendizagem.

O processo investigativo culminou com a saturação teóri$\mathrm{ca}$, a qual foi atingida com dez entrevistas, realizadas entre setembro de 2008 e abril de 2009. As entrevistas foram realizadas mediante o aceite do convidado e a assinatura do Termo de Consentimento Livre e Esclarecido (TCLE), e foram gravadas e, a seguir, transcritas.

A análise foi realizada de acordo com os pressupostos estabelecidos pela TFD, ou seja, os dados foram coletados,

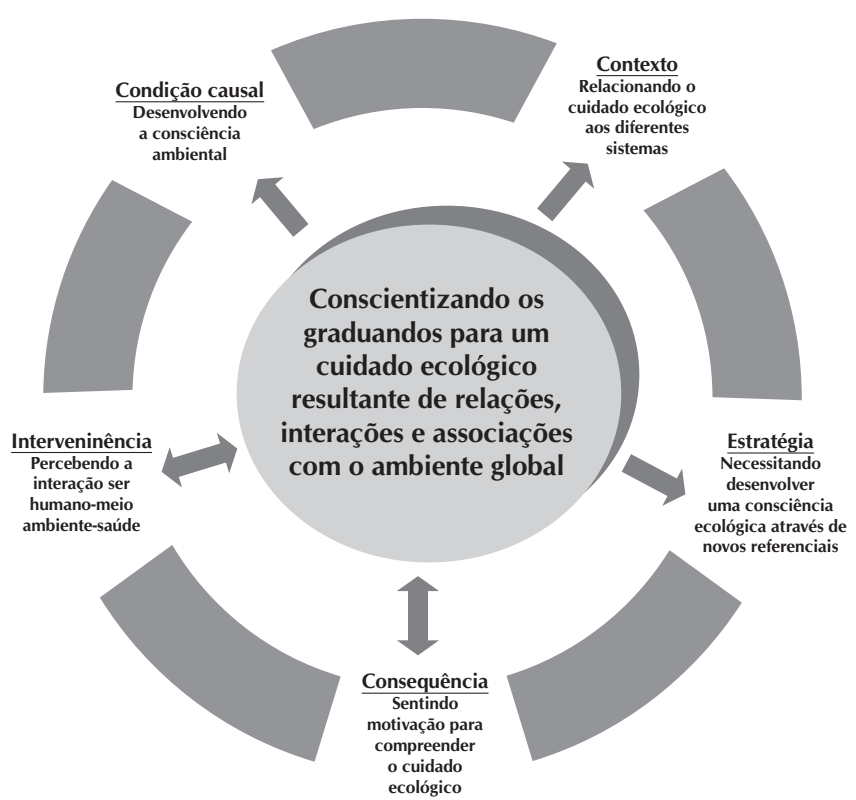

Figura 1: Integração das categorias à categoria ou tema central codificados e analisados simultaneamente e de forma comparativa. Cada nova entrevista, portanto, foi orientada pelas hipóteses que emergiram da análise das anteriores.

Os aspectos éticos do estudo foram contemplados por meio do cumprimento das recomendações da Resolução CNS $n^{\circ} 196 / 96^{(13)}$, que prescreve a ética na pesquisa com seres humanos no Brasil, a fim de validar a proposta de trabalho e poder divulgar as informações. O projeto foi aprovado pelo Comitê de Ética em Pesquisa com Seres Humanos da UFSC, sob o número 064/08.

Para preservar a identidade dos participantes, suas entrevistas foram denominadas por letras seguidas de um número equivalente à subcategoria na qual seu depoimento foi inserido, conforme o exemplo: A1, B3, C1, D2 e assim por diante.

\section{RESULTADOS}

O processo de coleta e análise dos dados culminou com a formulação da teoria formal: "Vislumbrando o cuidado ecológico como um fenômeno amplo e complexo", delimitada pelas seguintes categorias: 1) O cuidado ecológico como resultante das relações, interações e associações com o ambiente global (categoria central); 2) Desenvolvendo a consciência ambiental (condição causal); 3) Relacionando o cuidado ecológico aos diferentes sistemas (contexto); 4) Percebendo a interação ser humano-meio ambiente-saúde (interveniência); 5) Necessitando desenvolver uma consciência ecológica através de novos referenciais (estratégia); e 6) Sentindo motivação para compreender o cuidado ecológico (conseqüência).

A figura 1 representa o esquema teórico que integra as categorias ao tema ou categoria central, as quais se relacionam e se associam para originar a teoria formal Vislumbrando o cuidado ecológico como um fenômeno amplo e complexo.

De acordo com os estudantes, a Universidade não está sendo relevante no despertar/desenvolver uma consciência ecológica. Eles evidenciaram, por meio de suas falas, que a temática do cuidado ecológico somente foi abordada e problematizada quando esta veio associada indiretamente a outros saberes.

A gente teve algumas discussões em algumas aulas onde foi surgindo o assunto alimentos orgânicos. O que a gente comenta é que realmente é muito caro. Claro, é bom! Não sei se é tão seguro assim, porque tem muita gente que fala que não tem agrotóxico, mas é muito mais fácil um parasita se proliferar em alguém que não tem o agrotóxico... Mas o agrotóxico causa câncer, então é melhor ter uma boa higiene para garantir uma segurança alimentar, é melhor lavar muitas vezes do que consumir um agrotóxico. (A2)

O significado atribuído ao cuidado ecológico pelos estudantes está relacionado ao cuidado das pessoas e da saúde humana, à promoção do saneamento básico, do cuidado com o lixo, do evitar desperdícios, do olhar voltado para a população menos favorecida, da necessidade de melhorar as relações e interações entre os profissionais da saúde, dentre outros, os quais se relacionam a algumas disciplinas específicas da saúde. 
Estes significados, embora abordados de forma isolada por alguns docentes, não levaram em conta o Cuidado Ecológico como possibilidade de ampliação do conceito de saúde, pelas interações e associações sistêmicas. Em outras palavras, não levaram em consideração as múltiplas relações entre os seres vivos, a interação e a inter-relação entre eles, bem como as associações entre os seres humanos e demais seres que integram a natureza, por meio de um compromisso ético de responsabilidade consigo, com o outro e com o universo cósmico, de forma ampla e integradora.

O significado de cuidado ecológico, a partir do que foi citado anteriormente fica bastante expressivo na fala de uma das estudantes:

Para mim é desenvolver a consciência ambiental, é cuidar do meio ambiente..., é voltar os olhos para os problemas que a gente ta criando para que, no futuro, a gente ainda tenha onde morar, o que tomar, o que comer, realmente para mim é isto! É cuidar do que a gente ainda tem e não piorar, reverter todos esses efeitos deletérios que estão sendo feitos ao meio ambiente mas, na universidade se vê muito pouco! (A2)

A partir disso, o questionamento principal que norteou as intervenções com o segundo grupo amostral foi: Qual a função da universidade no despertar do cuidado ecológico para formação dos profissionais da área da saúde? No sentido de aprofundar a questão, buscou-se compreender quais as referências e estratégias utilizadas, ou que deveriam ser utilizadas, para despertar a consciência ecológica nos graduandos da área da saúde e a quem caberia esta importante função.

Para os docentes, o despertar da consciência ecológica é, além de uma necessidade emergente, um legado inegável, principalmente para os que têm a compreensão ampliada da realidade, visto que o grito do descuidado está à porta e requer intervenções, não apenas pontuais e assistencialistas, mas ações comprometidas com a transformação social e sustentabilidade ambiental, como expressa uma docente.

Oxalá possamos cuidar um dia por amor! Começando pelo amor a si mesmo, porque aí a sua consciência está tão ampliada que já abraçou tudo ao seu redor. (D3)

Os docentes, na sua maioria, fizeram pouca menção à função da universidade no que se refere ao processo de construção de uma consciência ecológica. Isoladamente, alguns abordaram a temática em sala de aula, mas somente quando esta se mostrou como um tema instigante. Para outros, a temática do cuidado ecológico não é função apenas da universidade, mas da sociedade em geral.

Tem todas as influências do aluno fora da universidade, que vão formar essa visão de cuidado ecológico... É uma mistura de tanta coisa, um pirão de tanta coisa que eu não sei se a universidade tem a obrigação de ensinar isso! Isso é de consenso, isso é de tudo, isso é de humanidade, isso não é de universidade, isso é de humanidade! (D3)
Os professores reconhecem, no entanto, que é preciso promover uma alfabetização no contexto local e global, como fica expresso nessa fala:

Há uma necessidade hoje de uma alfabetização ambiental [...] O ser humano é um analfabeto ambientalmente! (D1)

Para a maioria dos estudantes e docentes entrevistados, a questão ambiental/ecológica tomou dimensões avassaladoras e comprometedoras para a sustentabilidade ambiental e do próprio ser humano (vida humana). É uma temática, na concepção dos entrevistados, ainda bastante incipiente, tanto no discurso quanto na prática. Por ser o profissional do cuidado, o enfermeiro, no entender dos entrevistados, pode/deve ser considerado o profissional mais instrumentalizado para o cuidado da vida em sua dimensão sistêmica, conforme reflete uma das falas:

O profissional de enfermagem é o profissional hoje, na minha percepção, mais habilitado para cuidar da vida do planeta como um todo! Ele tem essa visão maior que o ambientalista, maior que o ecologista, porque os ecologistas estão muito voltados para a questão política, de preservação da espécie, preservação do planeta, são conservacionistas. A enfermagem, ela tem a capacidade - à medida que vai evoluindo nas discussões - de compreender a vida como um todo. Onde está o enfermeiro neste campo de discussões? (D1)

Os resultados evidenciaram, em suma, que existe uma inquietação em torno da problemática ambiental, tanto por parte dos discentes quanto dos docentes, mesmo que de forma ainda bastante incipiente e, por vezes, contraditória. A enfermagem é o curso que vem se destacando nas discussões, principalmente, por ter como foco de sua prática profissional o cuidado nas suas diferentes dimensões e expressões e também por ser o único curso entre os investigados, que tem uma disciplina especialmente voltada para o meio ambiente, denominada Saúde e Meio Ambiente.

\section{DISCUSSÃO}

Para o processo de construção de uma consciência ecológica - alfabetização ecológica - sustentada pela visão sistêmica, a universidade, mesmo com denotações divergentes, mostra-se como o principal espaço para o desenvolvimento de uma nova cultura, que tenha como meta a transformação social e a sustentabilidade ambiental.

Para buscar entender a complexidade ambiental, motivada pela visão sistêmica, é preciso levar em conta a história natural que foi desnaturalizada através da intervenção do pensamento no mundo, culminando com a tecnificação e economização do mundo dominado, que encontra agora o seu limite com o caos e a incerteza, que questionam a sustentabilidade como marca da crise existente e nos levam a pensar sobre a origem de sua existência na atualidade e sobre a possibilidade de um futuro sustentável ${ }^{(14)}$. 
A promoção da sustentabilidade ambiental não acontece somente mediante discursos teóricos. Esta requer a formação de atitudes inovadoras ou recriadoras, capazes de problematizar as diferentes situações, ou entornos, nos quais o ser humano está inserido, no sentido de proteger a vida em suas diferentes dimensões. Requer, ainda, estratégias e/ou novas possibilidades, socialmente responsáveis, a partir da integração das contradições e incertezas do tempo presente.

O paradigma dominante tem gerado insatisfações que tentam provocar o seu rompimento em favor da "defesa do pensamento ecológico com abrangência planetária, estabelecendo-se e respeitando-se legislações ambientalistas, bem como propagando a necessidade de se criar uma sociedade sustentável"(15). Mas, a quem interessa ou deveria interessar este assunto? Qual o papel da Universidade nesta questão? Qual o papel do enfermeiro neste campo de discussões?

A nova economia denominada capitalismo global, com instabilidades econômicas e seu potencial auto-destrutivo/ descartável, é insustentável do ponto de vista social e ecológico, porque tem como princípio o lucro e o consumismo acima de qualquer outro valor, como no caso dos direitos humanos, da proteção do meio ambiente e da democracia, motivo pelo qual precisa ser reestruturado, uma vez em que não será viável a longo prazo ${ }^{(16)}$.

Por outro lado, percebe-se que já iniciou a remodelação da globalização através do surgimento de comunidades sustentáveis, com base na alfabetização ecológica, juntamente com a prática do projeto ecológico, o qual envolve redes ecológicas de fluxos de matéria e energia, com o objetivo de promover a sustentabilidade da teia da vida ${ }^{(16)}$.

Neste cenário problematizador, permanece o questionamento: como vislumbrar o cuidado ecológico como um fenômeno amplo e complexo? O aprendizado da complexidade ambiental está relacionado à mudança de mentalidade, isto é, está relacionado a uma "transformação do conhecimento e das práticas educativas para construir um novo saber e uma nova racionalidade que orientem a construção de um mundo de sustentabilidade, de equidade, de democracia. É um re-conhecimento do mundo que habitamos"(14).

A ampliação do conceito de saúde proposta a partir da Reforma Sanitária, somada ao crescente processo de descentralização da saúde e às novas diretrizes curriculares, deve, gradativamente, instigar um papel transformador da realidade, tanto no campo das práticas de saúde como no campo da formação profissional.

As práticas educativas em saúde podem e devem ser consideradas a porta de entrada das novas gerações empreendedoras e/ou dos novos protagonistas sociais. Estes espaços oferecem a oportunidade para a criatividade e a formação de redes de solidariedade, fazendo com que a responsabilidade e o comprometimento estejam presentes tanto nas interações quanto nas ações que delineiam as políticas sociais e de saúde, numa visão sistêmica.

Nessa perspectiva, é fundamental integrar a interdisciplinaridade e a transdisciplinaridade na formação do ensino superior, considerando o ensino aprendizagem de forma articulada e contextualizada. O saber transdisciplinar renovado nos torna mais próximos do outro para conhecê-lo melhor e, no reconhecimento do saber do outro, buscar compreender o todo para estar mais próximo, também, da natureza ${ }^{(15)}$.

A teoria "Vislumbrando o cuidado ecológico como um fenômeno amplo e complexo", transcende as práticas pontuais e assistencialistas e possibilita a promoção do ser humano como sujeito e protagonista da sua própria história. Dito em outras palavras, o cuidado ecológico se dá mediante a valorização do diferente, a potencialização do ser humano como um ser de interações e associações, as quais precisam estar articuladas e integradas com os diversos saberes ${ }^{(17)}$.

Nesse sentido, o grande "desafio do século XXI é da mudança do sistema de valores que está por trás da economia global e globalizante, de modo a torná-lo compatível com as exigências da dignidade humana e da sustentabilidade ecológica"(16), uma vez em que o novo paradigma compreende a visão ecológica, a partir do entendimento da ecologia num sentido amplo e profundo ${ }^{(15)}$.

O conceito ampliado de saúde na perspectiva ecológica, requer do enfermeiro, seja por meio do ensino, da pesquisa ou da assistência, uma percepção crítica que leve em conta o saber, o ser e o fazer, comprometido com as transformações sociais e do cuidado com o meio ambiente como premissa para qualidade e existência da humanidade ${ }^{(15)}$. Requer assim, atitudes profissionais inovadoras e comprometidas com a conservação da vida e proteção do ambiente de cuidado.

\section{CONSIDERAÇÕES FINAIS}

Os significados que os discentes e docentes atribuíram ao cuidado ecológico assemelham-se no sentido de que o cuidado ecológico abrange a humanidade, devendo por isso ser trabalhado com todos os segmentos sociais, cujo aprendizado deve ser adquirido, principalmente, na família, mas também na educação básica e na universidade.

Para os estudantes dos diferentes cursos da área da saúde, a Universidade constitui-se num espaço privilegiado para o desenvolvimento e disseminação de uma cultura voltada para a sustentabilidade ambiental, enquanto para os docentes, a consciência ambiental requer uma consciência ampliada de si pra que seja possível ampliar a consciência para o outro e para o todo maior, o meio ambiente, no sentido de cuidar de ambos.

O cuidado ecológico como um fenômeno amplo e complexo, envolve relações, interações e associações comprometidas com a consciência e sustentabilidade ambiental, bem como com a transformação social. Nesse campo de discussões, o profissional enfermeiro ocupa um papel importante, pela compreensão do indivíduo como um ser integral e por meio das atitudes de cuidado como um fenômeno sistêmico. Por ser o profissional do cuidado, o enfermeiro pode/deve ser considerado o profissional mais instrumentalizado para o cuidado da vida na dimensão ecológico-sistêmica.

A Universidade é o espaço onde deve ocorrer a profissionalização de cidadãos críticos e comprometidos com a sociedade como um todo. Nessa direção, torna-se fundamental integrar a interdisciplinaridade e a transdisciplinaridade na 
formação do ensino superior, considerando o processo ensino aprendizagem de forma articulada e contextualizada.

O ambiente acadêmico constitui-se, em suma, em um espaço apropriado para o desenvolvimento de habilidades sistêmicas, capazes de contemplar as relações, interações e associações necessárias para a promoção e proteção da saúde, pela valorização e potencialização do meio ambiente como um bem público e social.

\section{REFERÊNCIAS}

1. Backes MTS, Erdmann AL, Backes DS. Cuidado ecológico: o significado para os profissionais de um hospital geral. Acta paul. enferm. 2009;22(2):183-91.

2. Ministério da Saúde(BR). Anais da VIII conferência nacional de saúde. Brasília: Ministério da Saúde; 1986.

3. Ministério da Saúde (BR). Ministério da Educação. Programa nacional de reorientação da formação profissional em saúde - Pró-Saúde: objetivos, implementação e desenvolvimento potencial. Brasília: Ministério da Saúde; 2005.

4. Brasil. Ministério da Saúde. Secretaria de Vigilância em Saúde. Política nacional de promoção da saúde. Brasília: Ministério da Saúde; 2006. (Série Textos Básicos de Saúde).

5. Azevedo E. Alimentos orgânicos: ampliando os conceitos de saúde humana, ambiental e social. Florianópolis: Insular; 2003.

6. Silva RF, Erdmann AL. Ambiente do cuidado: dimensão ecológica. Texto Contexto Enferm. 2002;11(3):72-82.

7. Geovanni T. Diagnóstico do ambiente: o espaço do corpo. In: Figueiredo NMA, Viana DL, organizadores. Fundamentos do uso de tecnologias na enfermagem. São Caetano do Sul (SP): Yendis, 2006. p. 129-147.

8. Morin E. Saberes globais e saberes locais: o olhar transdisciplinar. Rio de Janeiro: Garamond; 2004.

9. Boff L. Saber cuidar: ética do humano - compaixão pela terra. $11^{\text {a }}$ ed. Petrópolis: Vozes; 2004.
10. Junges, JR. Ética ambiental. São Leopoldo: Unisinos; 2004

11. Strauss A, Corbin J. Bases de la investigación cualitativa: técnicas y procedimientos para desarrollar la teoría fundamentada. Medelin: Universidad de Antioquia, Facultad de Enfermería, 2002. 323p.

12. Strauss A, Corbin J. Pesquisa qualitativa: técnicas e procedimentos para o desenvolvimento de teoria fundamentada. $2^{\mathrm{a}}$ ed. Porto Alegre: Artmed; 2008.

13. Ministério da Saúde (BR). Conselho Nacional de Saúde. Resolução CNS n. 196 de 10 de outubro de 1996. Aprova as diretrizes e normas regulamentadoras de pesquisas envolvendo seres humanos. Brasília (DF): Ministério da Saúde; 1996.

14. Leff E. A complexidade ambiental. São Paulo: Cortez; 2003.

15. Monteiro EMLM, Rolin KMC, Machado MFAS, Moreira RVO. A visão ecológica: uma teia na enfermagem. Rev Bras Enferm. 2005;58(3):341-4.

16. Capra F. As conexões ocultas: ciência para uma vida sustentável. 5ª ed. São Paulo: Cultrix; 2005.

17. Backes DS. Vislumbrando o cuidado de enfermagem como prática social empreendedora [tese]. Florianópolis (SC): Programa de Pós Graduação em Enfermagem, Universidade Federal de Santa Catarina. UFSC, Santa Catarina; 2008. 